\title{
Effect of carboplatin injection on Bcl-2 protein expression and apoptosis induction in Raji cells
}

\author{
Peng Lin, ${ }^{1}$ Boliang Zhou, ${ }^{2}$ Haiying Yao, ${ }^{1}$ Ya-ping Guo ${ }^{3}$ \\ ${ }^{1}$ Department of Hematology, Baoding First Central Hospital, Baoding, Hebei \\ ${ }^{2}$ Department of General Surgery, Baoding First Central Hospital, Baoding, Hebei \\ ${ }^{3}$ Department of Laboratory, Baoding First Central Hospital, Baoding, Hebei, China
}

\begin{abstract}
To investigate the effects of carboplatin (CBP) injection on apoptosis induction in the human lymphoma cell line Raji and to explore the underlying mechanism, Raji cells were randomly divided into two treatment groups. Cells in the experimental groups were treated with $15 \mu \mathrm{M}$ CBP injection, those in the control groups were treated with solvent, and both groups were treated for 24,48 and $72 \mathrm{~h}$. Cells from each group were collected for subsequent assays. For each group, the relative expression of B-cell lymphoma-2 (Bcl-2) was determined by Western blot (WB), the expression pattern of Bcl-2 was observed by immunocytochemistry (ICC), and cell apoptosis was observed after Hoechst 33342 staining. Real-time PCR detection of the relative expression levels of the Bax and caspase- 3 genes in each group of cells were performed. The WB results showed that the relative expression of the Bcl-2 protein significantly decreased 48 and $72 \mathrm{~h}$ after treatment in the CBP groups compared with the control groups $(\mathrm{P}<0.001)$, and a significant decrease in the expression of this protein was also noted at $48 \mathrm{~h} v s 24 \mathrm{~h}, 72 \mathrm{~h} v s 48 \mathrm{~h}$, and $72 \mathrm{~h} v s 24 \mathrm{~h}$ with extremely significant differences $(\mathrm{P}<0.001)$. Moreover, the expression of the $\mathrm{Bcl}-2$ protein decreased as the duration of CBP treatment increased, showing a time-dependent manner. The ICC results were consistent with the WB findings. The expression of the Bcl-2 protein in the CBP treatment group was significantly reduced $48 \mathrm{~h}$ and $72 \mathrm{~h}$ after treatment compared with the control group $(\mathrm{P}<0.001)$. A time-dependent manner was also noted in the expression of this protein, i.e., the expression level decreased gradually at 24,48 , and $72 \mathrm{~h}$ after treatment with statistically significant differences $(\mathrm{P}<0.001)$. Hoechst 33342 staining showed that the apoptosis rates at the three time points in the treatment groups were significantly higher than those in the control groups $(\mathrm{P}<0.001)$, and a time-effect relationship was observed. The apoptosis rate increased over time with a significant difference $(\mathrm{P}<0.05)$. The PCR results showed that the Bax and caspase-3 gene expression trend was the same but opposite that of Bcl-2. After treatment for $24 \mathrm{~h}$ and $48 \mathrm{~h}$, the gene expression of the medication groups decreased with a very significant difference $(\mathrm{P}<0.001)$, and with prolonged action time, the relative expression of the genes in the medication groups showed an upward trend. Comparing $48 \mathrm{~h}$ with $72 \mathrm{~h}$ and $24 \mathrm{~h}$ with $72 \mathrm{~h}$, the gene expression levels also increased, reaching a very significant difference $(\mathrm{P}<0.001)$, and there was a certain time dependence. CBP injection significantly reduced the expression of the Bcl-2 protein and induced apoptosis of Raji cells in a time-dependent manner. Moreover, CBP injection can increase the expression levels of the Bax and caspase- 3 genes.
\end{abstract}

Key words: Carboplatin injection; Raji cells; Bcl-2; cell apoptosis.

Correspondence: Peng Lin, Department of Hematology, Baoding First Central Hospital, 320 Great Wall North Street, Baoding, Hebei 071028, China. Tel. +86.13933897479. E-mail: ojifrx@163.com

Contributions: PL, HY, carried out the studies, participated in collecting the data, drafted the manuscript and were responsible and accountable for the accuracy and integrity of the work; BZ, YG, performed the statistical analysis and participated in the study design; PL, BZ, participated in the acquisition, analysis, or interpretation of the data and drafted the manuscript. All the authors have read and approved the final version of the manuscript and agreed to be accountable for all aspects of the work.

Conflicts of interest: The authors declare that they have no competing interests, and all authors confirm accuracy.

Funding: This research received no specific grant from any funding agency in the public, commercial, or notfor-profit sectors.

Availability of data and materials: All data generated or analyzed during this study are included in this published article.

Ethical approval: The study was approved by the Institutional Ethics Committee of Baoding First Central Hospital, Baoding, Hebei, China.

Informed consent: Not applicable. 


\section{Introduction}

Lymphoma is a malignant tumor originating from lymph. As a common and frequent disease that is difficult to cure and comes with a high mortality rate, lymphoma seriously threatens human life and health. The etiology of lymphoma is complicated and may involve factors including gene mutations, bacterial infections, and autoimmune defects. Clinical manifestations of lymphoma include enlarged lymph nodes, an enlarged spleen, and systemic symptoms such as fever and pruritus, ${ }^{1-4}$ and commonly used treatment regimens are radiotherapy, chemotherapy, bone marrow transplantation, and surgery. Lymphoma is divided into Hodgkin lymphoma and non-Hodgkin lymphoma. Hodgkin lymphoma generally has a good prognosis. The 5-year survival rate of non-Hodgkin lymphoma is only approximately $30-40 \%$. Although many treatments are available for this disease, lymphoma is difficult to cure due to the high heterogeneity of this tumor and the inconsistency between patients. ${ }^{5-7}$ In addition, studies have found that the prognosis of this disease is poor. Therefore, the discovery of effective chemotherapeutics and biological agents is very important for the treatment of lymphoma. Carboplatin, as the second generation of platinum compounds, has a broad range of antitumor effects and has been widely valued in recent years. Its main function is to act on guanine in DNA, destroying DNA molecules, interfering with DNA synthesis, and producing toxic effects on cells. Previous studies have demonstrated that Carboplatin injection is useful to treat various malignant tumors in the clinical setting, including non-smallcell lung cancer (NSCLC), liver cancer, ovarian cancer, and neuroblastoma. Studies on its treatment of lymphoma, however, have rarely been reported. ${ }^{8-11}$

The development and progression of tumors, including lymphoma, are closely related to cell proliferation and apoptosis. Effective induction of apoptosis and inhibition of proliferation of tumor cells have become a new direction in tumor therapy. ${ }^{12,13}$ Apoptosis involves the activation, expression and regulation of a series of genes, among which the Bcl-2, caspase-3 and Bax genes play a key role. ${ }^{14-18} \mathrm{Bcl}-2$ is an antiapoptotic protein that inhibits cell apoptosis, and the Bax protein promotes cell apoptosis. Bcl-2 and Bax can form dimers, and the ratio of the two proteins affects the survival of tumor cells. ${ }^{19,20}$

Raji is a human B-lymphoma leukemic cell line that is used as a preferred model for the discovery of chemotherapy drugs. ${ }^{21}$ The aim of the present study was to determine the expression of the antiapoptotic protein Bcl-2 and the morphological changes in Raji cells after treatment with $\mathrm{CBP}$ injection and to investigate the effects of CBP injection on apoptosis induction in Raji cells.

\section{Materials and Methods}

\section{Cell culture}

Raji cells were purchased from the cell bank of the Shanghai Institute of Cell Biology, CAS, and cultured in RPMI-1640 medium supplemented with $10 \% \mathrm{FBS}$ and $2 \mathrm{mmol} / \mathrm{L}$ glutamine at $37^{\circ} \mathrm{C}$ in a $5 \% \mathrm{CO}_{2}$ atmosphere. Carboplatin was purchased from Qilu Pharmaceutical Co., Ltd. (Jinan, China) and supplied as $100 \mathrm{mg}$ in $10 \mathrm{~mL}$ of solution (lot number: H20020180). Cells in the logarithmic growth phase were selected and divided into two groups according to the experimental protocol. Cells in the experimental group were treated with $15 \mu \mathrm{M}$ CBP injection, and those in the normal control group were treated with solvent. Cells in each group were collected at 24,48 , and $72 \mathrm{~h}$ after treatment for subsequent assays.

\section{Western blot}

Cells were harvested after treatment and lysed with RIPA lysis buffer (P0100; Solarbio, Beijing, China) containing $1 \mathrm{mM}$ phenylmethane on ice for $5 \mathrm{~min}$. After centrifugation at $12000 \mathrm{rpm}$ at $4^{\circ} \mathrm{C}$ for $10 \mathrm{~min}$, the supernatant was collected to obtain total protein. The concentration of proteins was determined using a BCA protein assay kit (PC0020; Solarbio, Beijing, China). According to the Western blot protocol, proteins were loaded and separated on $8 \%$ SDS-PAGE and then transferred onto a PVDF membrane (IPVH00010; Millipore, Billerica, MA, USA). The membrane was blocked with $5 \%$ nonfat milk, and the anti-Bcl-2 primary antibody (diluted 1:500; WL01556; Wanleibio, Shenyang, China) was added and incubated at $4^{\circ} \mathrm{C}$ overnight. After washing with TBST, the membrane was incubated with horseradish peroxidase-labeled goat anti-rabbit igg (diluted 1:3000; SE134; Solarbio). The internal reference $\beta$-actin was similarly processed. Finally, ECL solution (PE0010; Solarbio) was added to the membrane followed by exposure to X-ray film in a dark room. The film was developed and scanned, and the optical density value of the target band was analyzed with a gel image processing system (Gel-Pro-Analyzer software).

\section{Immunocytochemistry}

Polylysine-coated coverslips were used, and the treated cells were grown on a coverslip and fixed with $4 \%$ paraformaldehyde solution for $15 \mathrm{~min}$. After the formaldehyde was discarded, $0.1 \%$ Triton X-100 was added followed by incubation for $20 \mathrm{~min}$. The solution was then removed, and the cells were washed with $0.01 \mathrm{M}$ PBS 3 times for 5 min each time. After the PBS was discarded, 3\% $\mathrm{H}_{2} \mathrm{O}_{2}$ was added followed by incubation for $15 \mathrm{~min}$, and washing with $0.01 \mathrm{M}$ PBS 3 times for $5 \mathrm{~min}$ each time. The PBS was discarded, and serum was added to block for $15 \mathrm{~min}$. The serum was then removed, and anti-Bcl-2 antibody (diluted 1:100; WL01556; Wanleibio) was added followed by incubation overnight at $4^{\circ} \mathrm{C}$. The primary antibody was discarded, and the cells were washed with $0.01 \mathrm{M}$ PBS 3 times for $5 \mathrm{~min}$ each time. After the PBS was discarded, HRP-labeled goat anti-rabbit secondary antibody (diluted 1:100 with PBS; g1213, Servicebio, Wuhan, China) was added to completely cover the cells and incubated at $37^{\circ} \mathrm{C}$ for $60 \mathrm{~min}$. The secondary antibody was discarded, and the cells were washed with $0.01 \mathrm{M}$ PBS 3 times for 5 min each time. DAB was added for color development, and then the cells were counterstained with hematoxylin (g1004-100; Servicebio). The cells were mounted and observed under a microscope. Photos were taken, and optical density was analyzed using Image-Pro Plus software.

\section{Hoechst 33342 staining}

Raji cells were cultured on a coverslip in a 12 -well plate. After the designated time, the culture medium was discarded, and the cells were washed with PBS twice. Fixative $(0.5 \mathrm{~mL})$ was added to the cells to fix at room temperature for $10 \mathrm{~min}$. The fixative was removed, and the cells were washed with PBS twice for 3 min each time. After the PBS was aspirated, $0.5 \mathrm{~mL}$ of Hoechst 33342 staining solution (g1011; Servicebio) was added to the well followed by incubation for $5 \mathrm{~min}$, and the staining solution was discarded. At the same time, a drop of anti-fluorescence quenching mounting medium was dropped onto the slide and covered with the coverslip that was grown with cells. The stained cells on the slide were observed with a fluorescence microscope, and photos were taken. The apoptotic rate was calculated as the number of apoptotic cells/total number of cells $\times 100$.

\section{Real-time fluorescence quantitative PCR (qrt-PCR)}

Real-time fluorescence quantitative PCR was used to detect the relative expression of the Bax and caspase- 3 genes in each group of cells. According to the trizol extraction kit (15596026; 
Thermo Fisher Scientific, Waltham, MA, USA) experimental instructions, total RNA was extracted from the cells, and the RNA concentration was detected using a NanoDrop 2000 (Thermo Fisher Scientific). An Invitrogen reverse transcription kit (K1691; Thermo Fisher) was used for reverse transcription. Different primers were designed based on the Bax and the caspase- 3 genes. The primer sequences are shown in Table 1 and were synthesized by Biotechnology Co., Ltd. (Shanghai, China). PCR using $2 \times$ Power Taq PCR mastermix (PR1702; Biotek, Beijing, China) and SYBR Green I (SY1020; Solarbio, Beijing, China) was performed on a fixed light quantifier. The relative expression of these two genes was calculated by the formula $2^{-\Delta \Delta C T}$.

\section{Statistical analysis}

Data are presented as the mean \pm SD. SPSS 20.0 was used for statistical analysis of data, and graphpad Prism 8.0 was used for plotting. One-way ANOVA was used for $t$-tests, and P-values of less than 0.05 were considered to be statistically significant.

\section{Results}

\section{CBP reduced the expression of the $\mathrm{Bcl}-2$ protein in the WB assay}

According to the experimental design, cells in each group were treated for 24,48 , and $72 \mathrm{~h}$ and then collected for protein extraction. The relative expression of the anti-apoptotic protein Bcl-2 in each group was determined by WB assay, and the results showed that the expression of the Bcl-2 protein after 48 and $72 \mathrm{~h}$ of treatment significantly decreased in the CBP treatment group compared with that of the control group with an extremely significant difference. A significant decrease in the expression of this protein was also noted at $48 v s 24 \mathrm{~h}, 72$ vs $48 \mathrm{~h}$, and 72 vs $24 \mathrm{~h}$ in a time-dependent manner, and the difference was also extremely significant (Figure $1 \mathrm{~A}, \mathrm{~B}$ ).

\section{CBP reduced the expression of the Bcl-2 protein by ICC}

Cells were grown on coverslips, and the expression and distribution of Bcl-2 were determined by ICC. The mean values of optical density were used to quantitatively analyze the photos obtained. The results showed that the expression of the Bcl-2 protein in the CBP treatment groups at 48 and $72 \mathrm{~h}$ after treatment was

Table 1. Primer sequences.

\begin{tabular}{lcc} 
Primer name & Pre primer $(5-3)$ & Post primer $(5-3)$ \\
Bax & Caspase-3 & TAGCAAACTGGTGCTCAAGG \\
GACGACAGGGTGCTACGAT & GGGTCCCGAAGTAGGAAAGG & TTTCCTTACGCTCTGACTGA \\
\hline
\end{tabular}

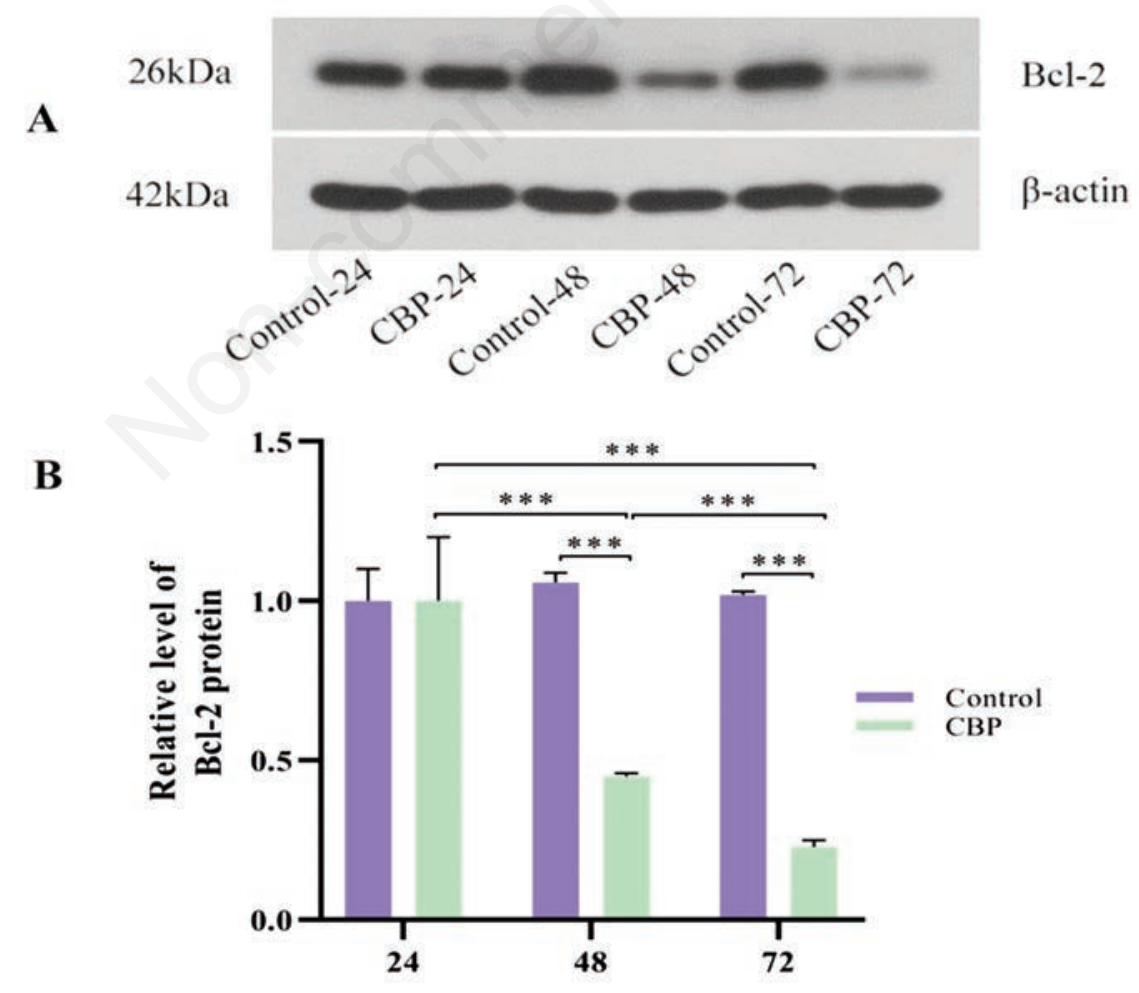

Figure 1. Bcl-2 protein expression in different groups by WB analysis. A) Expression of the Bcl-2 protein decreased in the CBP-48 and CBP-72 groups compared with that of the Control-48 and Control-72 groups, respectively, and the difference was extremely significant $\left({ }^{* * *} \mathbf{P}<0.001\right)$. B) Expression of Bcl-2 protein was reduced in the CBP-48 and CBP-72 groups compared with the CBP-24 and CBP-48 groups, respectively, with an extremely significant difference $(* * * \mathrm{P}<0.001)$. 
significantly decreased compared with that of the control group, and the difference was extremely significant; an extremely significant difference was also observed in the CBP treatment group after 48 and $72 \mathrm{~h}$ of treatment $v s 24 \mathrm{~h}$ and the difference between the $72 \mathrm{~h}$ and $48 \mathrm{~h}$ CBP treatment groups was statistically significant. Moreover, the effect increased over time in a time-dependent manner (Figure $2 \mathrm{~A}, \mathrm{~B}$ ).

\section{CBP promoted Raji cell apoptosis in the Hoechst 33342 staining assay}

Apoptosis of Raji cells was observed by Hoechst 33342 staining, and the apoptosis rate was calculated for each group. The results showed that cell apoptosis was enhanced in the CBP treatment groups after 24,48 , and $72 \mathrm{~h}$ of treatment compared with that of the control group, and the difference was extremely significant. In the CBP treatment group, the cell apoptosis rate significantly increased after 48 and $72 \mathrm{~h}$ compared with that at 24 and $48 \mathrm{~h}$, respectively, with a statistically significant difference, and the cell apoptosis rate was significantly increased at $72 \mathrm{~h} v s 24 \mathrm{~h}$, with an extremely significant difference. The apoptosis rate increased with prolongation of CBP treatment in a time-dependent manner (Figure $3 \mathrm{~A}, \mathrm{~B}$ ).

\section{PCR results show that carboplatin can increase the expression levels of the Bax and caspase- 3 genes}

The relative expression levels of the Bax and Caspase- 3 genes in each group were detected. The test results showed that Bax and Caspase- 3 had the same expression trend, which was the opposite trend as that of Bcl-2. After 24 and $48 \mathrm{~h}$ of treatment, the expression levels of these two genes in the medication group were significantly reduced, with a very significant difference; with prolonged time, the relative expression levels of these genes in the medication group showed an upward trend. Compared with $48 \mathrm{~h}$ and $72 \mathrm{~h}$, and $24 \mathrm{~h}$ and $72 \mathrm{~h}$, the gene expression level also significantly increased in muscle, reaching a very significant difference level with a certain time dependence (Figure 4 A,B).

\section{Discussion}

In the present study, Raji cells were treated with CBP injection at a designated concentration, and the expression of the anti-apoptotic protein Bcl-2 was determined by WB and ICC. Cell apoptosis was observed by Hoechst 33342 staining. It was found that the expression of the Bcl-2 protein was significantly inhibited and

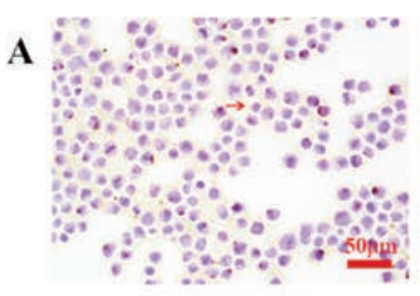

Control-24

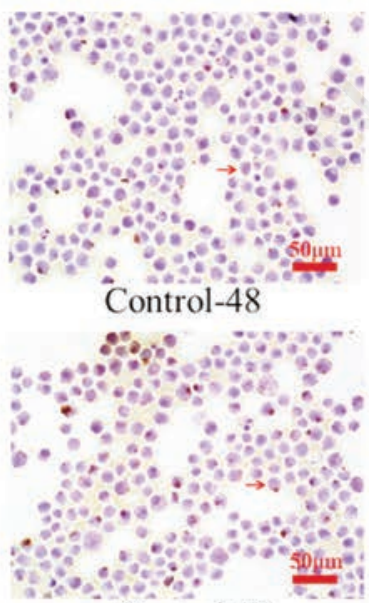

Control-72

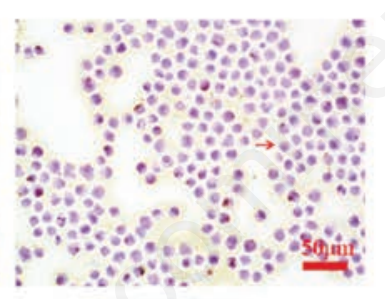

CBP-24

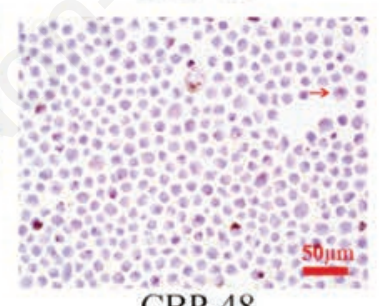
CBP-48

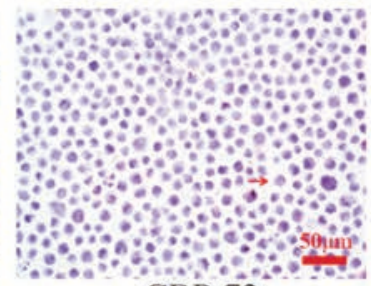

CBP-72
B

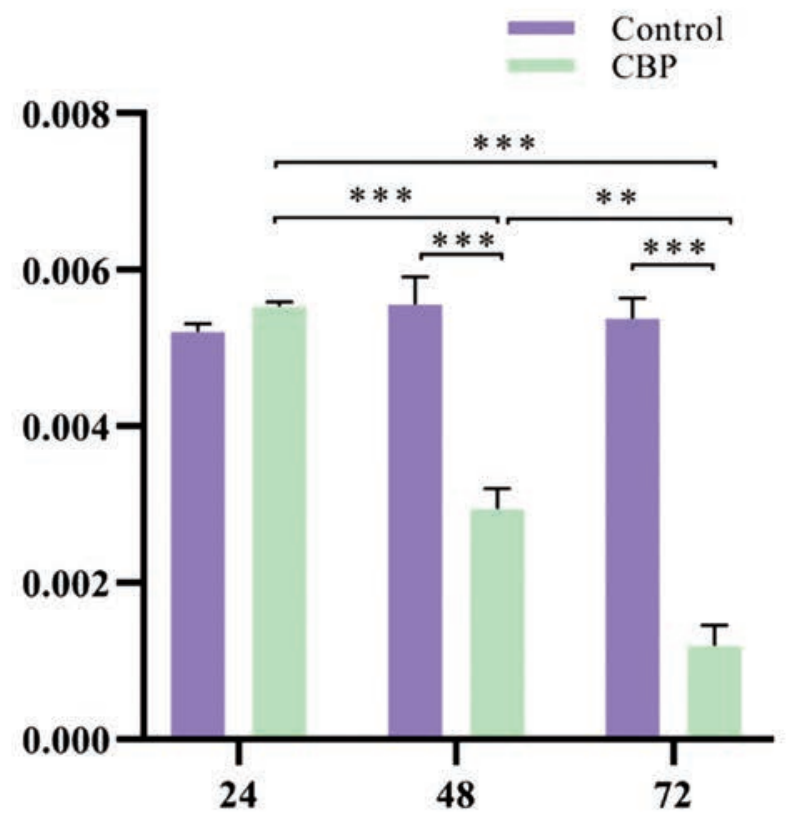

Figure 2. Bcl-2 protein expression in different groups by ICC. A) Expression of the Bcl-2 protein decreased in the CBP-48 and CBP72 groups compared with that in the Control-48 and Control-72 groups, respectively, and the difference was extremely significant $(* * * \mathbf{P}<0.001)$. B) Expression of the Bcl-2 protein was reduced in the CBP-48 and CBP-72 groups compared with the CBP-24 group with an extremely significant difference $\left({ }^{* * *} \mathrm{P}<0.01\right)$, and the level of this protein was significantly decreased in the CBP-72 group compared with that of the CBP-48 group $(* * \mathrm{P}<0.01)$. 
apoptosis was induced in Raji cells after CBP treatment, and the effects of CBP increased as the duration of CBP treatment increased in a time-dependent manner. We also found that the difference in $\mathrm{Bcl}-2$ expression at $24 \mathrm{~h}$ was not obvious, presumably due to the short action time of the drug, which was not sufficient to affect molecular level changes.

Lymphoma is a malignant tumor that originates in lymph nodes and lymphoid tissues. The clinical manifestations of this disease include painless enlarged lymph nodes and systemic symptoms such as fever and weight loss. ${ }^{22}$ Lymphomas can be divided into two classes based on their pathology, namely, non-Hodgkin lymphoma (NHL) and Hodgkin lymphoma (HL). Generally, the incidence of NHL is much higher than that of HL. ${ }^{23-25}$ Due to the different etiologies and clinical features, the main treatments include chemotherapy for NHL and a combination of radiotherapy and chemotherapy for HL. Some chemotherapy agents are effective in inhibiting the spread of tumor cells, and patients can be cured in clinical practice. HL is a tumor that can be cured by chemotherapy, and the efficacy and prognosis of NHL have also been significantly improved.

Chemotherapy agents commonly used in cancer treatment include doxorubicin, dexamethasone, adriamycin, vincristine and others. ${ }^{26}$ In addition, carboplatin and cisplatin, both platinum- based anticancer agents, have been of concern, and cisplatin-based or cisplatin-containing chemotherapy schemes account for $70-80 \%$ of all treatments. ${ }^{27}$ The advantages of cisplatin include a strong anticancer effect and activity and a toxicity spectrum that is different from other anticancer agents, making it favorable to combine with other anticancer drugs for a better outcome. Cisplatin has been widely used to treat various tumors, such as NSCLC, thyroid cancer, breast cancer, liver cancer, and osteosarcoma. ${ }^{28-30}$ Carboplatin, also a platinum compound, can inhibit cell proliferation and promote cell apoptosis ${ }^{31}$ and has been proven to be effective in cancer treatment. It was shown in the present study that carboplatin promotes the apoptosis of lymphoma cells and inhibits the expression of Bcl-2 (an antiapoptosis-related protein) in Raji cells. Nevertheless, we have to consider the problem of tumor resistance. The mechanisms of tumor resistance include drug efflux, tumor cell gene mutation and DNA damage repair. After the chemotherapeutic drug is used for a period of time, tumor cells will highly express the pump P-glycoprotein to pump the drug out of the cell, reducing the drug concentration and reducing the drug effect; tumor cells can also mutate certain genes to escape the inhibitory effects of the drug. In addition, tumor cells can alleviate their genetic damage through DNA damage repair and carry out normal life activities. Cunning tumor cells are always struggling with

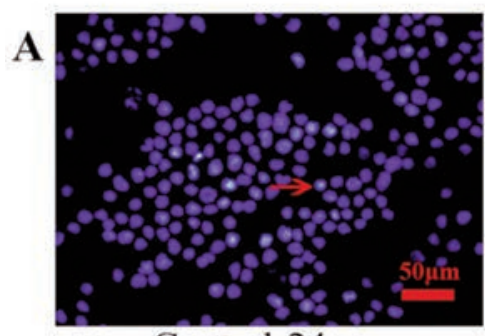

Control-24

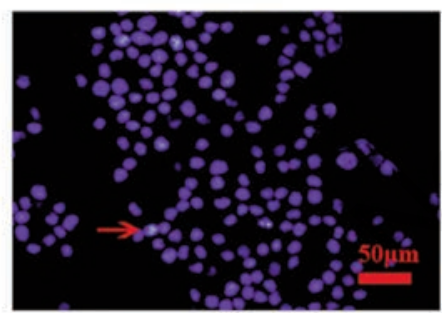

Control-48

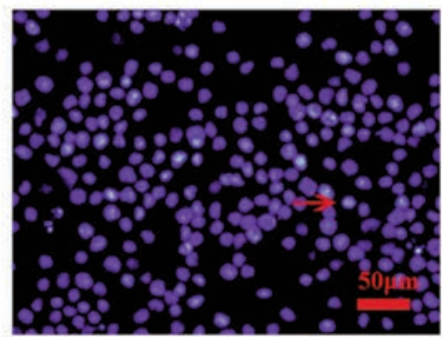

Control-72

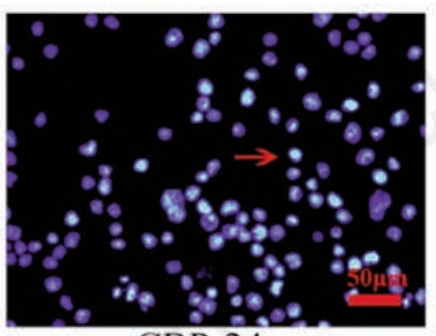

CBP-24

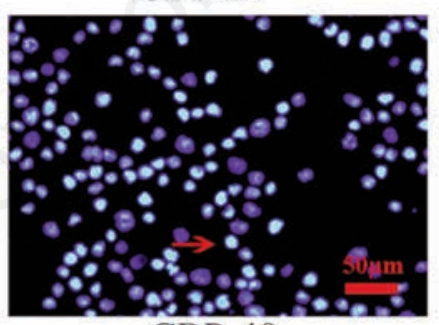

CBP-48

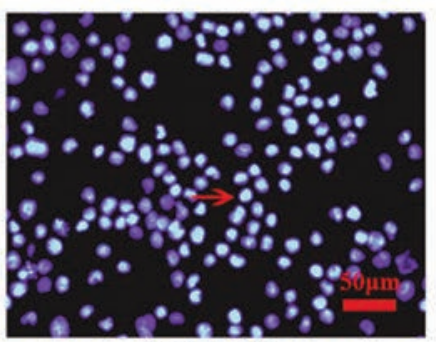

CBP-72

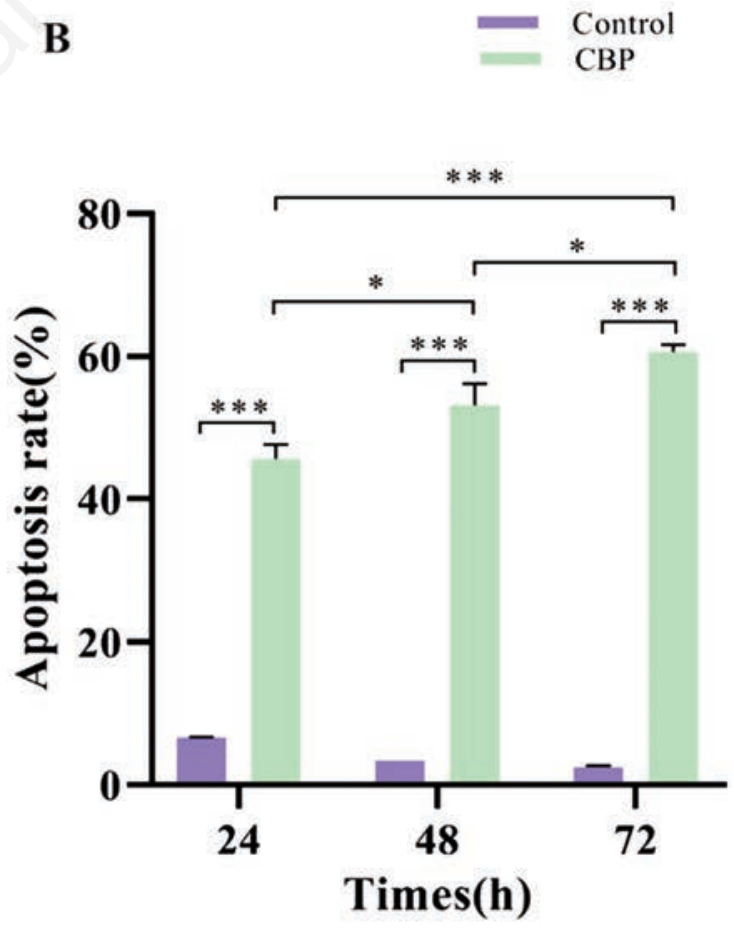

Figure 3. Hoechst 33342 staining results showed that the apoptosis rate in the CBP treatment groups at 24, 48, and $72 \mathrm{~h}$ significantly increased compared with that of the respective control groups, and the difference was extremely significant $(* * * P<0.001)$. The apoptosis rate in the CBP group at $72 \mathrm{~h}$ was significantly increased compared with that at $24 \mathrm{~h}$ with an extremely significant difference $\left({ }^{* * *} \mathrm{P}<0.001\right)$. The apoptosis rates in the CBP-48 and CBP-72 groups increased compared with those in the CBP-24 and CBP-48 groups, respectively, and the difference was statistically significant $(* \mathbf{P}<0.05)$. 
$\mathbf{A}$

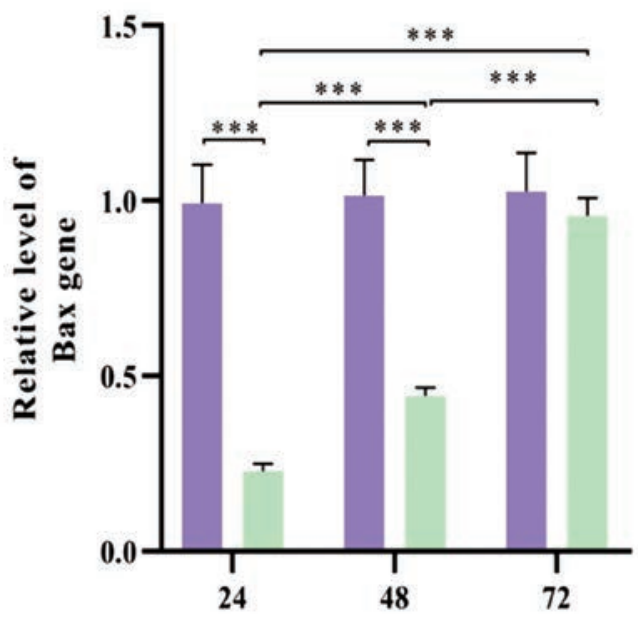

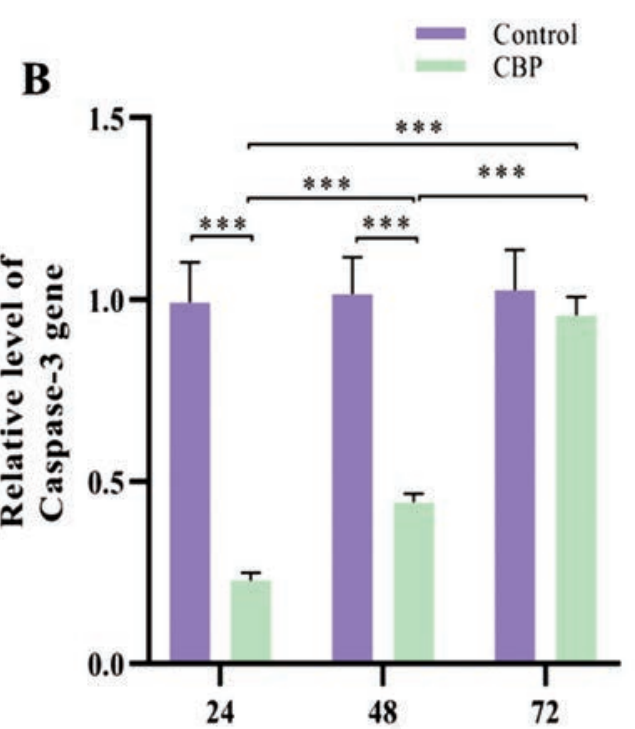

Figure 4. Expression of the Bax and caspase- 3 genes in different groups. Compared with CBP-24 and Control-24, and CBP-48 and Control-48, the expression of CBP-24 was significantly decreased, with a significant difference $(* * * P<0.001)$. CBP-48 and CBP-24, CBP-72 and CBP-48, and CBP-72 and CBP-24 all showed significant differences $\left({ }^{* * *} \mathrm{P}<0.001\right)$.

treatment methods. In addition to researching and developing more efficient chemotherapy drugs, a timely response to tumor resistance is an important way to resist tumors.

$\mathrm{Bcl}-2$ is an important protein in the process of apoptosis and interacts with other related proteins, such as caspase, Bax, and p53, to ensure this biological process. ${ }^{32} \mathrm{Bcl}-2$ is involved in the occurrence and development of laryngeal cancer, gliomas, squamous cell carcinoma and many other tumors and plays an important biological function. ${ }^{33-34}$ The molecular mechanism of these genes will be clarified with the development of research, which will provide extensive ideas for the development of novel chemotherapy agents and molecular targeted therapies. Hopefully, breakthrough progress in the treatment of cancers will be made, and cures for cancers can be expected in the near future.

\section{References}

1. Frederik HS, Steffen H. Lymphoma of the eyelid. Surv Ophthalmol 2017;62:312-31.

2. James G, Michael JL, Sonali MS. An update in treating transformed lymphoma. Best Pract Res Clin Haematol 2018;31: 251-61.

3. Jiang ML, Bennani NN, Andrew LF. Lymphoma classification update: B-cell non-Hodgkin lymphomas. Expert Rev Hematol 2017; 10:405-5.

4. Ilia NB. Pediatric lymphoma. Pediatr Rev 2017;38:410-23.

5. Stephen MA. Hodgkin lymphoma: Diagnosis and treatment. Mayo Clin Proc 2015;90:1574-83.

6. Bastian VT, Craig H M. Treatment of relapsed and refractory Hodgkin lymphoma. Semin Hematol 2016;53:180-5.

7. Von Baumgarten L, Illerhaus G, Korfel A, Schlegel U, Deckert M, Dreyling M. The diagnosis and treatment of primary CNS lymphoma. Dtsch Arztebl Int 2018;115:419-26.

8. Leslie RB, Franco MM. Carboplatin/paclitaxel induction in ovarian cancer: The finer points. Oncology (Williston Park) 2018;32:418-20, 422-4.
9. Zhu X, Xu J, Cai H, Lang J. Carboplatin and programmed death-ligand 1 blockade synergistically produce a similar antitumor effect to carboplatin alone in murine ID8 ovarian cancer model. J Obstet Gynaecol Res 2018;44:303-11.

10. Fujita T, Hiroishi T, Shikano K, Yanagisawa A, Hayama N, Amano H, et al. The safety and efficacy of treatment with nabpaclitaxel and carboplatin for patients with advanced squamous non-small cell lung cancer concurrent with idiopathic interstitial pneumonias. Intern Med 2018;57:1827-32.

11. Liu Z, Yang W, Long G, Wei C. Trace elements and chemotherapy sensitivity. Biol Trace Elem Res 2016;173:283-90.

12. Douglas R. Cancer and apoptosis: Who is built to last? Cancer Cell 2017;31:2-4.

13. Szymon K. Apoptosis: Its origin, history, maintenance and the medical implications for cancer and aging. Phys Biol 2016;13:031001.

14. Robyn LS, Andreas S, Grant D. BCL-2: Long and winding path from discovery to therapeutic target. Biochem Biophys Res Commun 2017;482:459-69.

15. Knight T, Luedtke D, Edwards H, Taub JW, Ge Y. A delicate balance - The BCL-2 family and its role in apoptosis, oncogenesis, and cancer therapeutics. Biochem Pharmacol 2019;162:250-61.

16. Delbridge AR, Grabow S, Strasser A, Vaux DL. Thirty years of BCL-2: translating cell death discoveries into novel cancer therapies. Nat Rev Cancer 2016;16:99-109.

17. Rumani S, Anthony L, Kristopher S. Regulation of apoptosis in health and disease: The balancing act of BCL-2 family proteins. Nat Rev Mol Cell Biol 2019;20:175-93.

18. Lee HJ, Lee EK, Seo YE, Shin YH, Kim HS, Chun YH, et al. Roles of Bcl-2 and caspase- 9 and -3 in CD30-induced human eosinophil apoptosis. J Microbiol Immunol Infect 2017;50:145-52.

19. Ramadan MA, Shawkey AE, Rabeh MA, Abdellatif AO. Expression of P53, BAX, and BCL-2 in human malignant melanoma and squamous cell carcinoma cells after tea tree oil treatment in vitro. Cytotechnology 2019;71:461-73.

20. Mahdav S, Khodarahmi P, Roodbari N H. Effects of cadmium on $\mathrm{Bcl}-2 / \mathrm{Bax}$ expression ratio in rat cortex brain and hip- 
pocampus. Hum Exp Toxicol 2018;37:321-8.

21. Wang ZC, Liu Y, Wang H, Han QK, Lu C. Research on the relationship between artesunate and Raji cell autophagy and apoptosis of Burkitt's lymphoma and its mechanism. Eur Rev Med Pharmacol Sci 2017;21:2238-43.

22. Emiliano NM, Nilanjan G. Lymphoma. Prim Care 2016;43:661-75.

23. James OA, Randy DG, Matthew AL. Non-Hodgkin lymphoma. Lancet 2017;390:298-310.

24. John TS. Non-Hodgkin lymphoma in children. Curr Hematol Malig Rep 2015;10:237-43.

25. Hu B, Ryan J, Nilanjan G. Checkpoint inhibitors Hodgkin lymphoma and non-Hodgkin lymphoma. Curr Hematol Malig Rep 2018;13:543-54.

26. Cagel M, Grotz E, Bernabeu E, Moretton MA, Chiappetta DA. Doxorubicin: nanotechnological overviews from bench to bedside. Drug Discov Today 2017;22:270-81.

27. Gwo YH, Natasha W, Jermaine IGC. Cisplatin versus carboplatin: comparative review of therapeutic management in solid malignancies. Crit Rev Oncol Hematol 2016;102:37-46.

28. Jody CC, Liang Y, Heather AW. Neoadjuvant and adjuvant therapy for non-small cell lung cancer. Hematol Oncol Clin North Am 2017;31:31-44.

29. Freeman J, Crowley PD, Foley AG, Gallagher HC, Iwasaki M,
Ma D, et al. Effect of perioperative lidocaine and cisplatin on metastasis in a murine model of breast cancer surgery. Anticancer Res 2018;38:5599-606.

30. Boot A, Huang MN, Ng AWT, Ho SC, Lim JQ, Kawakami Y, et al. In-depth characterization of the cisplatin mutational signature in human cell lines and in esophageal and liver tumors. Genome Res 2018;28:654-65.

31. Kenmotsu H, Yoh K, Mori K, Ono A, Baba T, Fujiwara Y, et al. Phase II study of nab-paclitaxel + carboplatin for patients with non-small-cell lung cancer and interstitial lung disease. Cancer Sci 2019;110:3738-45.

32. Yao C, Cao X, Fu Z, Tian J, Dong W, Xu J, et al. Boschniakia rossica polysaccharide triggers laryngeal carcinoma cell apoptosis by regulating expression of Bcl-2, caspase-3, and P53. Med Sci Monit 2017;23:2059-64.

33. Qiu X, Chen Y, Yuan J, Zhang N, Lei T, Liu J, et al. Functional BCL-2 rs2279115 promoter noncoding variant contributes to glioma predisposition, especially in males. DNA Cell Biol 2019;38:85-90.

34. Olie RA, Hafner C, Küttel R, Sigrist B, Willers J, Dummer R, et al. Bcl-2 and bcl-xl antisense oligonucleotides induce apoptosis in melanoma cells of different clinical stages. J Invest Dermatol 2002;118:505-12. 